\title{
El diálogo de Ellacuría con Marx y el marxismo
}

Héctor Samour

Departamento de Filosofía Universidad Centroamericana "José Simeón Cañas"

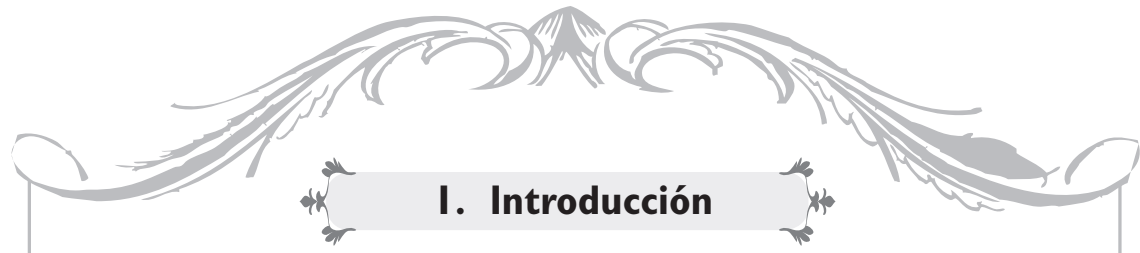

Para comprender cabalmente el diálogo de Ignacio Ellacuría con Marx y el marxismo es importante aludir al contexto histórico en que dicho diálogo se produce. Hacia finales de la década de los años sesenta, Ellacuría orienta su actividad intelectual hacia el análisis crítico de los problemas humanos y sociales que caracterizaban la realidad histórica de América Latina y del Tercer Mundo, ${ }^{1}$ especialmente los generados por la violencia revolucionaria y la violencia institucionalizada como expresiones de una situación de injusticia y opresión. ${ }^{2}$

Es una época en la que Ellacuría participa en el movimiento de transformaciones que se están produciendo en la Iglesia latinoamericana después de la Segunda Conferencia del Episcopado Latinoamericano en Medellín, en la renovación de la Compañía de Jesús de cara al problema social en América Latina a partir de la 'Carta de Río' de todos los provinciales latinoamericanos (mayo de 1968) y en la experiencia de las nuevas organizaciones eclesiales de base que alimentará el surgimiento de la teología de la liberación. Todo ello en un contexto de crisis social y política caracterizada por la emergencia de movimientos revolucionarios y de organizaciones populares que buscaban la transformación de las estructuras capitalistas vigentes hacia formas sociales y políticas de carácter socialista.

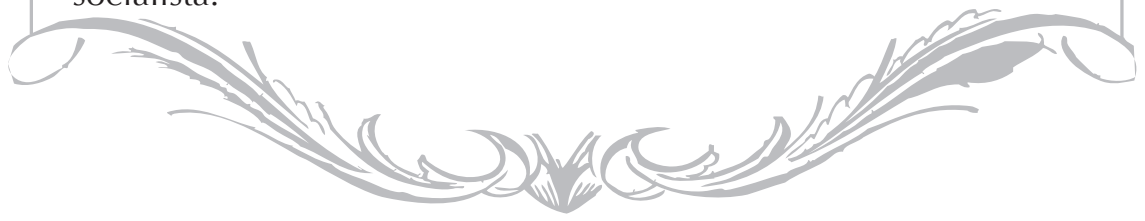


Tanto los documentos de Medellín como la 'Carta de Río' proponían una redefinición de la Iglesia a la luz de la pobreza de la mayoría de los pueblos latinoamericanos y del Tercer Mundo y propugnaban el abandono del paradigma del "desarrollo" con su reformismo y su sustitución por el paradigma de la "liberación" con su consiguiente exigencia ideológica y política más radical para superar la injusticia estructural. Este cambio de paradigma estaba sustentado teóricamente por la Ilamada teoría de la dependencia, que criticaba fuertemente el modelo de desarrollo de los países industrializados y la iniciativa desarrollista impulsada en América latina a través de la Alianza para el Progreso del presidente Kennedy. ${ }^{3}$ Sus autores argumentaban que el desarrollismo había profundizado la dependencia estructural de los países subdesarrollados con relación a los países industrializados sin poder resolver sus problemas económicos y sociales. ${ }^{4}$

En este contexto histórico, Ellacuría asume la interpretación de la realidad histórica latinoamericana elaborada por el Ilamado socialismo latinoamericano, ${ }^{5}$ esto es, el pensamiento social y político generado por los intelectuales latinoamericanos influidos por la teoría de la dependencia y el análisis marxista de la sociedad y la historia. Por muchos capítulos, el análisis socioeconómico de la teoría de la dependencia venía a confirmar la tesis filosófica de la importancia de la historicidad como ámbito privilegiado de la realización humana y de conocimiento de la realidad, al tiempo que su interpretación sociológica de la situación latinoamericana fundamentaba la racionalidad de la exigencia ética de liberación y la necesidad de que tanto la filosofía y la teología latinoamericanas se reconstituyeran en función liberadora para dar una respuesta efectiva a la situación fundamental de injusticia, realizando así su radical historicidad. Las tesis de este socialismo que más influyeron en el pensamiento de Ellacuría son las siguientes:

a. El carácter histórico del subdesarrollo. La situación de subdesarrollo de América Latina es resultado de un proceso histórico cristalizado en las distintas estructuras nacionales, en el que el subdesarrollo de unas naciones está vinculado estructuralmente al desarrollo de otras. El subdesarrollo no es un estado atrasado y anterior al capitalismo, sino una consecuencia de él y una forma particular de su desarrollo. ${ }^{6}$ La dominación-dependencia es así resultado de un proceso histórico injusto y no de una necesidad natural. Por ello no es posible una liberación histórica al margen de una recomposición del sistema económico, entendido como un todo. "No 
puede intentarse la realización de la justicia al margen de una profunda revolución en el orden socioeconómico ni una plena realización del hombre sin poner en juego una adecuada estructura económica".?

b. El método histórico-estructural. El enfoque de la dependencia concibe los procesos históricos como procesos de concreción sucesiva, de formación y destrucción de estructuras. Es un proceso permanente que debe ser analizado en cada instante y en cada situación desde las determinaciones del proceso histórico universal y del conjunto de determinaciones que permitan estudiar en cada situación lo que hay de concreto y específico. ${ }^{8}$ De acuerdo con ello, el hecho del que debe partirse es el hecho histórico no como mero dato fijo que está ahí, sino como una realidad que viene-de y va-a como momento de un proceso de desarrollo unitario, cuya explicación tiene que ser genética y estructural a la vez. El supuesto filosófico de este proceder es que "la realización del ser humano y de la sociedad no se da en términos puramente naturales, sino en términos de realización histórica $y$, por tanto, ninguna configuración histórica particular agota todo lo que la realidad humana es y puede dar de sí en su hacerse y realizarse" ${ }^{\prime \prime}$ c. La historia como lugar concreto universal. La concreción actual de la historia, lejos de invalidar sus resultados, es el lugar privilegiado de la universalidad. Hay en la historia accidentes empíricos, pero lo que ocurre en ella tiene carácter de universalidad en la forma de una comunidad estructural. Ellacuría ya afirmaba en ese período: "Es en el conjunto de la historia donde se realizan la totalidad del hombre y de la sociedad, no por mera aglomeración cuantitativa sino por desenvolvimiento cualitativo".$^{10}$ La historia se convierte así en patentización de la realidad total, "de lo que absolutamente es (del absoluto) pero en la exigencia de una positiva realización comunitaria y de una correcta interpretación racional". ${ }^{11}$ Si bien se dan negaciones y contradicciones, no hay por qué negar racionalidad a la historia, por más que sus características no sean las naturales o dependan en parte de realizaciones libres.

d. Desde este punto de vista, es imposible la consideración del subdesarrollo como fenómeno concreto si no se toma en cuenta como referencia global el proceso de totalización que implica la historia occidental, de la cual esta historia singular no es más que una forma de concreción específica. 
e. Este carácter universal de la dimensión histórica es destacado por la teoría de la dependencia (en sus diversas formulaciones) al considerar el proceso de subdesarrollo latinoamericano -y en general de los países subdesarrollados- como una forma singular de concreción de una historia universal que es mucho mayor y que, en determinado momento, implica la historia del capitalismo occidental. La historia aparece así como un solo proceso universal que estructura dinámicamente a todos los pueblos. "Hay una sola historia universal única, en la que no solo hay coetaneidad de diversas historias parciales, sino una sola historia que dinamiza unitariamente cualquier proceso realmente histórico".$^{12}$

\section{f. La liberación como tarea histó-} rica de los pueblos oprimidos. La teoría de la dependencia patentiza el hecho de que la estructura relacional opresora de la historia actual está anulando aquellas relaciones sin las que no es posible una plena humanización y una convivencia social justa: "Sobre este Tercer Mundo las naciones dominantes proyectan sus estructuras de producción y sus estructuras de consumo, mediante la producción de plusvalía y su realización en el mercado, para lograr la apropiación del excedente económico. Es esta realización de la plusvalía en el mercado lo que cierra el proceso y manifiesta lo que es la llamada sociedad de consumo. Por lo que toca a la producción pone en juego factores capitales de la realización humana y por lo que toca al consumo duplica las condiciones de dominación [...] En su más cruda verdad, la sociedad de consumo y su raíz, la sociedad de producción, están consumiendo al hombre y al mundo, lo están deshaciendo" ${ }^{13}$ De ahí que la tarea histórica fundamental de los países oprimidos económica, política, cultural y religiosamente se caracterice por ser una tarea de liberación. La liberación en sentido negativo implicaría la supresión de unas relaciones humanas y de unas estructuras viciadas; $y$ en sentido positivo, exigiría la construcción de posibilidades para unas relaciones humanas solidarias en unas estructuras fundamentalmente justas. ${ }^{14}$

En su artículo "Función liberadora de la filosofía" de 1985, Ellacuría planteaba que la filosofía no nace de la admiración ni de la angustia, sino de la protesta frente a las situaciones de injusticia y deshumanización. ${ }^{15}$ En Ellacuría no se puede disociar su reflexión filosófica de su biografía y de lo que en cada momento inspira su compromiso vital con la búsqueda 
de la verdad y su realización en la vida humana. Si en su etapa juvenil Ellacuría afirmaba la intención humanista y liberadora de su filosofar frente a la inautenticidad de la existencia y el vacío espiritual en las sociedades capitalistas occidentales, a partir de aquí lo afirmará frente al hecho de la existencia de mayorías pobres y de pueblos oprimidos en el contexto de una estructuración mundial injusta en la que priman relaciones de dependencia y dominación. De cara a esta situación, es la totalidad de la historia la que debe ser liberada y humanizada.

\section{El diálogo con Marx y el marxismo}

Es desde este contexto histórico-cultural que Ellacuría ve la necesidad de entablar, desde la filosofía de Zubiri, un diálogo con Marx y el marxismo con el fin de encontrar una fundamentación teórica más sólida que ilumine una adecuada acción histórica liberadora. Para Ellacuría, la metafísica no es ajena a la realidad histórica y, por lo que toca a la filosofía, querer dedicarse al tratamiento de esa realidad sin una sólida metafísica y una no menos sólida antropología es como querer dedicarse al tratamiento de las enfermedades sin una sólida base científico-médica. Lo demás es puro curanderismo, que algunas veces resulta, pero que a la larga es catastrófico.

En realidad, Ellacuría dialoga con toda la tradición hegelianomarxista, incluyendo a la teoría crítica de la Escuela de Francfort, y hay abundantes textos que reflejan este diálogo. Pero aquí solo me referiré a la lectura e interpretación que hace de Marx y del marxismo.
Para él, la filosofía de Marx, como la de Hegel, pertenecen a aquellas filosofías que han conceptuado la historia como ámbito de máxima densidad de lo real. En el caso de Hegel, el diálogo y la confrontación con su metafísica se vuelve imprescindible a la hora de fundamentar una filosofía histórica. $Y$ esto por dos razones principales: en primer lugar, porque Hegel es uno de los principales interlocutores de Zubiri, además de las similitudes, a contrario sensu, que tiene su teoría de la realidad con el realismo materialista abierto zubiriano, en la que desaparecen zonas específicas de lo real para convertirse la estructura dinámica de la realidad en el objeto de la metafísica; en segundo lugar, porque si bien es cierto que en Hegel se da la culminación última del movimiento filosófico europeo, que se inició con Descartes, influido por el horizonte cristiano de la creación, ${ }^{16}$ es por Hegel que la historia entra de Ileno en la metafísica, al postular que al ser le compete 


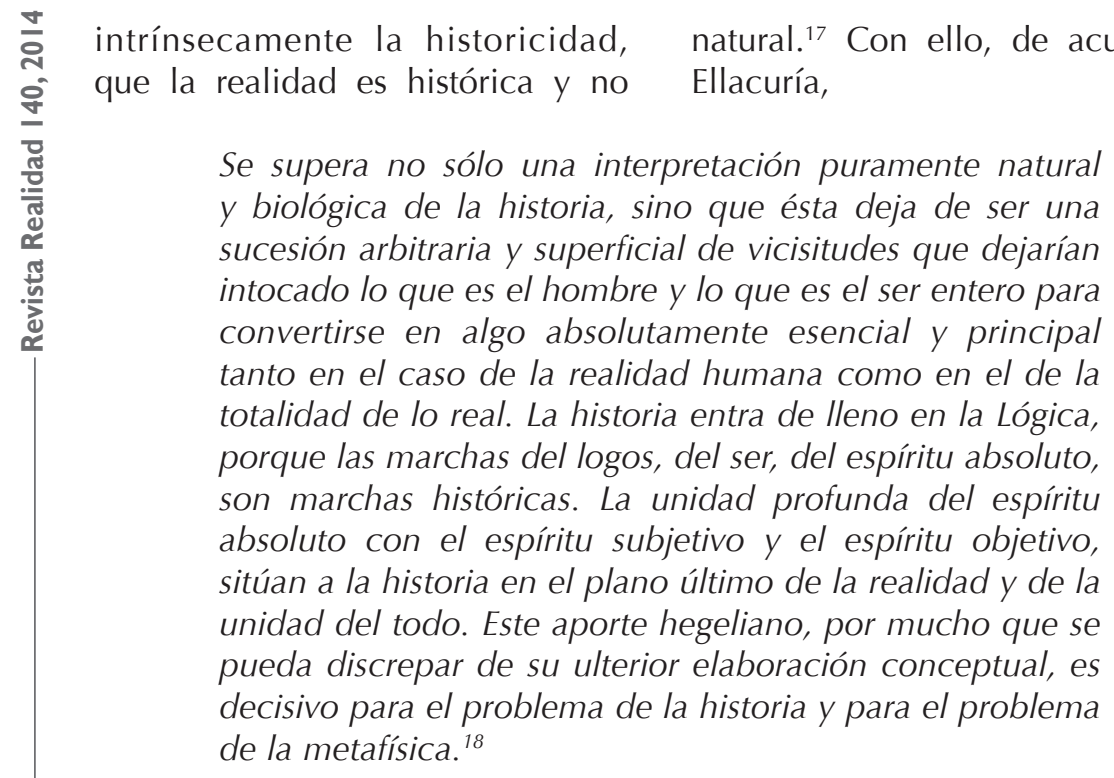

Marx ha sido el gran realizador de la idea hegeliana del carácter histórico de la realidad y del conocimiento como parte y momento de ella. El materialismo histórico, a diferencia de la trans-física del materialismo dialéctico de Engels, ${ }^{19}$ lleva a una metafísica en la que se le da a la historia el valor profundo que ya había recibido de manos de Hegel, aunque interpretada materialísticamente; es en la materia dinámica donde se expresa el principio de lo real, pero la explicación última no está en el principio de la materia, sino en su proceso y en su última etapa de realización, que es la realidad socioeconómica en su proceso dialéctico-histórico. ${ }^{20}$

Por otro parte, en el campo epistemológico, el análisis marxista lleva a preguntarse por el lugar adecuado para hacer una teoría desideologizada. El lugar adecuado es ponerse en el lugar de las clases dominadas en cuanto pretenden contradecir esa dominación. Si de lo que se trata es de crear nuevas expresiones teóricas más inmunes a la ideologización, el lugar apropiado será el que patentice mejor las necesidades objetivas, tal como se aprecian en las mayorías oprimidas. ${ }^{21}$

Finalmente, para Ellacuría hay una razón más que justifica el diálogo con Marx, y que tiene que ver con la necesaria dimensión política de toda filosofía por el mismo carácter histórico y político de la totalidad de realidad. Marx Ileva a la práctica filosófica la tesis de que tanto la realidad en su última concreción, como la configuración 
histórica de toda aproximación real, se estructuran desde lo político. En esta línea, Ellacuría señala que Marx no se contentó con ser un filósofo especulativo, sino que desde la forma concreta en que se le presentaba la realidad en la que estaba inmerso intentaba interpretarla en vista de su transformación. Pero se trataba de la inmersión en una realidad política a la que buscaba interpretarla en vista a una transformación sociopolítica. Por ello se puede decir que el filosofar de Marx es un modelo de un filosofar político ejercitado desde un logos histórico, esto es, de un logos que sintetiza la necesidad de comprensión y de transformación de la realidad histórica. En el desarrollo de su pensamiento se muestra la necesidad de ir a una praxis política, como condición sine qua non para la realización misma de la realidad y, por ende, de la filosofía. ${ }^{22}$ En definitiva, según Ellacuría, Marx "ha establecido la necesidad de lograr una teoría que realmente pueda convertirse en praxis histórica y de lograr una praxis que responda realmente a las exigencias de la teoría". ${ }^{23}$

Desde un punto de vista histórico-metafísico, Ellacuría ubica a Hegel y Marx en la corriente de la filosofía moderna, que se inició con Descartes, en la que se le da más densidad metafísica a la historia que a la naturaleza. En efecto, Ellacuría señala que desde Descartes, pasando por Kant, cada vez más se ha ido dando una preferencia ontológica a la historia, desechando más la naturaleza. Y si bien se ha ido entendiendo por historia un concepto muy equívoco y ambiguo, este ha sido lo suficientemente amplio como para indicar un ámbito distinto al de naturaleza, que sería el ámbito de la interioridad, la subjetividad. ${ }^{24}$ Así el cogito cartesiano supone una vuelta a la subjetividad como lugar propio de la filosofía y, por ende, de la metafísica; el estudio transcendental kantiano de la razón humana deja en claro, finalmente, que para hacer metafísica hay que regresar al ser humano como realidad personal y libre. ${ }^{25}$ Por ello no es arbitrario afirmar que hay un esfuerzo en todo el subjetivismo post-cartesiano por querer montar una metafísica, ya no sobre la naturaleza, que es una realidad pobre, sino sobre la realidad humana, que es donde se expresa más realidad. Donde hay más realidad es en la persona humana, la sociedad y la historia.

Para Ellacuría, con el descubrimiento de la subjetividad, se pasa a concebir lo último de la realidad en términos más subjetivos, por el radical cambio que se da en la concepción del sujeto desde el hypokeimenon griego al Subjekt germánico como Ich o Bewusstsein. ${ }^{26}$ Esto, visto en retrospectiva y a la luz del horizonte de la historicidad, no hay que interpretarlo falsamente como el paso de realismo al idealismo, sino como 
el paso del fisicismo (naturalismo) al subjetivismo real; por lo tanto, como una ampliación y un perfeccionamiento del concepto mismo de lo último; esto es, como una aproximación histórica a la historicidad como concepto de lo último, la cual, tras el siglo XIX, habría adquirido plena vigencia como horizonte de la filosofía.

Esto ocurre justamente a partir de Hegel, quien recupera para la metafísica la historicidad como lugar por excelencia de realización y plenificación del Absoluto. ${ }^{27}$ En este sentido, Ellacuría ve su propuesta de la realidad histórica como objeto último de la filosofía como una continuación, pero a la vez como una superación, de esta tradición filosófica, especialmente de la tradición hegeliano-marxista. De ahí que afirme que su propuesta de la historia como objeto y punto de partida de la filosofía no es un capricho ni un a priori dogmático:

Ha sido labor de la historia de la filosofía misma, que paulatinamente ha ido descubriendo y mostrando dónde y en qué forma se da la realidad por antonomasia, donde se da la mayor densidad de lo real. Los que sostenían que la persona humana como realidad metafísica era el summum de realidad; los que sostenían que lo era la existencia humana o la vida humana; los que defendían que era la historia..., todos ellos se acercaban a la definición del objeto de la filosofía como realidad histórica. ${ }^{28}$

En esta tradición filosófica, lo que la filosofía de Marx aporta, según Ellacuría, es que la interpretación de la realidad de la filosofía moderna no tiene por qué ser idealista, aunque lo sea normalmente en la filosofía moderna. Ellacuría considera que el materialismo histórico es un intento de interpretación materialista o realista de la modernidad, a diferencia de una interpretación subjetivista o idealista de la misma. En efecto, lo que Marx aporta es una interpretación materialista de la historia, a diferencia de la interpretación idealista de Hegel. Pero no se trata, según Ellacuría, de una interpretación a la manera de un materialismo naturalista, ni siquiera en el sentido de que a la materia le pertenece por sí misma un dinamismo dialéctico, sino que se trata de otro tipo de materia cuya investigación correcta se logra a través de las ciencias sociales, especialmente de las ciencias económicas. El materialismo histórico de Marx es una concepción materialista de la historia y no una concepción fisicista de la materia natural, que sería la propia del materialismo dialéctico, en el que la metafísica se convierte en una filosofía positiva de la naturaleza. 
En este sentido, para Ellacuría, el expresión de la filosofía marxista. ${ }^{29}$ materialismo histórico es la mejor

\section{Materialismo dialéctico y materialismo histórico}

Ellacuría entiende que esta interpretación rompe con aquellas interpretaciones marxistas que conciben la dialéctica materialista como una visión unitaria que abarca tanto el materialismo dialéctico y el materialismo histórico, pero que reducen el materialismo histórico al materialismo dialéctico $\mathrm{o}$, incluso, que conciben el materialismo dialéctico como una especie de metafísica general en el sentido clásico, en la que el materialismo histórico queda asumido como una filosofía regional. Por ello, Ellacuría

ve necesario analizar el planteamiento metafísico de ambos y ver si el materialismo histórico pende o no de las tesis metafísicas del materialismo dialéctico.

Para Ellacuría, el planteamiento radicalmente metafísico tanto del materialismo dialéctico como del materialismo histórico estaría en la pregunta sobre la relación del pensar y del ser, tal y como la plantea Engels en aquel famoso texto de su Ludwig Feuerbach:

El gran problema cardinal de toda la filosofía, especialmente de la moderna, es el problema de la relación entre el pensar y el ser [...] El problema de la relación entre el pensar y el ser, entre el espíritu y la naturaleza, problema supremo de toda la filosofía [...] problema que, por lo demás, tuvo gran importancia en la escolástica de la Edad Media; el problema de saber qué es lo primario, si el espíritu o la naturaleza, este problema revestía, frente a la Iglesia, la forma agudizada siguiente: ¿el mundo fue creado por Dios, o existe desde toda una eternidad? ${ }^{30}$

Lo propio del materialismo dialéctico, a diferencia del materialismo histórico de Marx, está en que entiende el espíritu como pensar y el ser como naturaleza. El materialismo histórico no admitiría en varios sentidos esta disyunción de espíritu y naturaleza y, desde luego, no dejaría a la naturaleza la prioridad en la explicación de la verdadera realidad, si es que se entiende por naturaleza aquello que es objeto de las ciencias físicas. Para Ellacuría, el problema principal del materialismo dialéctico es que maneja un concepto de materia muy pobre, tal y como se deduce de la definición que de ella da Lenin en Materialismo y Empiriocriticismo: 
La materia es una categoría filosófica que caracteriza la realidad objetiva, la que se le da al hombre en sus sensaciones, la que es copiada por nuestras sensaciones, fotografiada y reproducida, y que existe con independencia de ellas [...] La única propiedad de la materia, que el Materialismo se ve obligado a reconocer, es la propiedad de ser realidad objetiva, de existir fuera de nuestra conciencia. ${ }^{31}$

Aquí se expresa una visión muy reducida de la materia que la entiende únicamente como aquello que puede percibirse por los sentidos, como un hecho bruto comprobado por lo que determinan objetivamente de ella las ciencias naturales. Pero los sentidos, afirma Ellacuría, nunca nos darán lo que es la materia, por más que se pudiera admitir que toda materia fuera captable por los sentidos:

Hoy sabemos más de la materia, pero este saber ha ido enriqueciendo de tal modo el concepto de materia que ésta no sólo aparece hoy más plena, sino también más enigmática. Pensar que sabemos ya lo que es la materia y cuáles son sus límites, manejar el concepto de materia a partir de lo que son las cosas materiales perceptibles por nuestros sentidos, es cerrarnos a una comprensión adecuada de la realidad. Creer que la materia ha de ser imaginable, representable porque lo sean las cosas materiales, es salirse del recto camino. La materia como principio de lo que son las cosas materiales no es ni puede ser una especie de entelequia inmaterial, que nada tenga que ver con lo que son las cosas materiales; pero tampoco tiene por qué ser - y las ciencias lo van mostrando día a día- algo semejante a las cosas materiales. Ni el embrión es un homúnculo ni la materia un corpúsculo. ${ }^{32}$

Además, afirmar que la única propiedad de la materia es la de ser realidad objetiva, es una afirmación injustificada, muy vaga y superficial, que no aclara lo que es la materia como realidad. ${ }^{33} \mathrm{EI}$ problema básico del materialismo dialéctico, igual al del materialismo decimonónico, es que parte de un concepto muy pobre de sensibilidad como reflejo objetivo de la materia exterior, oscureciendo las diferencias radicales entre la sensibilidad meramente animal y la sensibilidad humana, cuyo constitutivo formal es la impresión de realidad. La sensibilidad animal en tanto impresión de estimulidad actualiza las cosas como algo meramente "objetivo", pero nunca como "de suyo", como 
realidad. El "de suyo" absorbe y supera la objetividad, pero la mera objetividad no alcanza el "de suyo". De acuerdo a Diego Gracia, ${ }^{34}$ esta tesis fundamental del "sensismo realista" de Zubiri proporciona la base para una fundamentación más radical del materialismo filosófico a la proporcionada por el "sensismo objetivista" de la doctrina de los materialistas del siglo XIX y del materialismo dialéctico.

La determinación de la realidad de la materia, del "de suyo" material, solo puede hacerse desde la realidad que se actualiza en la sensibilidad humana de las cosas materiales. Pero no a la manera de un acto de abstracción u organización de la inteligencia desde el caos de las sensaciones ofrecidos por los sentidos, bajo el supuesto de la presunta independencia y objetividad de la materia externa, sino siguiendo el hilo de la verdad real como análisis de la realidad actualizada en la aprehensión sentiente. En este sentido, la determinación de lo que sea la realidad de la materia allende de lo actualizado en la aprehensión -esto es, de sus notas constitutivas o esenciales- es obra de la razón y, por ello, es una tarea abierta. Apoyado en esta tesis, Ellacuría acusa a Engels de ingenuidad, por creer que lo que decían las ciencias naturales de su época sobre la materia era ya saber lo que es la materia. ${ }^{35}$

Lo más grave es que a la materia así entendida se le dan características metafísicas, incluso con características semejantes a lo que es el Absoluto en Hegel, o a lo que es Dios en la teología: la materia es eterna, increada, imperecedera. ${ }^{36}$ Para explicar el movimiento intrínseco de la materia se recurre a la dialéctica. La dialéctica supone que la realidad no es un agregado de cosas sino un todo unitario interdependiente, que está en perpetuo movimiento y actividad. Ambas características son esenciales a la dialéctica hegeliana, pero en el materialismo dialéctico se aplican primariamente a la naturaleza. ${ }^{37}$ Las mismas leyes de la dialéctica son tomadas tal cual de la Lógica de Hegel y propuestas como las leyes más generales de la naturaleza y de la historia. ${ }^{38}$

Ellacuría señala que en el marxismo ortodoxo (especialmente en el marxismo soviético) la raíz filosófica -metafísica- de toda la concepción marxista está en esta interpretación dialéctica de la materia natural. A esta materia natural se accedería a través de las ciencias naturales, que serían las más aptas para superar toda forma de idealismo y aun toda forma de ideología. La metafísica sería, entonces, una especie de trans-ciencia, donde el trans está dado principalmente por la interpretación dialéctica de la materia, pero también por una especie de absolutización de las ciencias naturales. ${ }^{39}$ En este sentido, puede hablarse de una reducción científica 
de la metafísica, principalmente porque la realidad última y total está entendida desde la captación de las ciencias naturales. Ciertamente en esta metafísica hay una concepción dialéctica de la materia con posibilidades para entender la materia social e histórica como una realidad cualitativamente distinta -en virtud, sobre todo, de la ley del paso de la cantidad a la cualidad-, pero en realidad esta última propende a quedar entendida o desde la materia natural o como una mera regionalización del concepto general de materia.

Para Ellacuría, el materialismo histórico, por el contrario, tiende a concebir -more hegeliano- la realidad como totalidad unitaria y dialéctica del proceso material que abarcaría a una el momento natural y el momento histórico, siendo la metafísica la conceptuación de esa unidad dinámica real. Desde este punto de vista, la metafísica no sería ya una filosofía de la naturaleza ampliada a la materia histórica pero dependiente fundamentalmente de los aportes de las ciencias naturales, sino una concepción de la realidad material que la entiende desde su última aparición en su forma histórica, con el consiguiente abandono de cualquier inspiración fisicista (naturalista). ${ }^{40}$

En este sentido, el materialismo histórico entiende la pregunta por la relación entre el pensar y el ser de una forma más radical a como la entiende el materialismo dialéctico, pues el ser no sería la materia natural, sino la materia histórica. En efecto, a esta pregunta el materialismo histórico respondería que hay unidad a pesar de la distinción: "El pensamiento y el ser son, pues, ciertamente distintos, pero al mismo tiempo forman juntos una unidad" ${ }^{41}$

Para Ellacuría, esta unidad del pensamiento y del ser ha tenido una doble superación: una primera superación hegeliana de Parménides y una segunda superación marxiana de Hegel. El problema ha tenido, pues, por lo menos tres etapas: una etapa parmenídea, una etapa hegeliana y una etapa marxiana. La superación hegeliana de Parménides, entre otras muchas diferencias, radicaría en la introducción de la dialéctica. Pensar y ser no son de inmediato una identidad, porque entonces el Absoluto sería absoluto desde su primer momento y no tendría nada que hacer. Precisamente lo que ocurre en el proceso necesario del Absoluto, que es el proceso necesario de toda la realidad, es que en ese primer momento no hay identificación estática o contemplativa entre lo que es y el pensar de eso que es. Hay una dualidad fundamental, $y$ es justamente esa dualidad la que va a obligar a una serie de alienaciones y recorridos. Se trata de una identificación, pero de una identificación activa y procesual, esto es, de una identidad que se hace y se va haciendo en proceso. Pero esta 
superación hegeliana de Parménides no le satisface a Marx, y por ello ve la necesidad de superarla.

La superación marxiana de Hegel estriba, según Ellacuría, en la comprensión de la conciencia desde el ser y no el ser desde la conciencia. Pero este ser tiene unas características determinadas y su producción no sería la naturaleza sin más, sino la realidad socioeconómica en su proceso dialéctico histórico. La naturaleza es asumida en esa realidad socioeconómica como un momento intrínseco de ella, pero irreductible a ella. Es una concepción materialista, porque es en la materia dinámica donde se expresa el principio de lo real y no en un espíritu o autoconsciencia. Pero es un materialismo histórico, porque la explicación última de lo real no está en el origen de la materia, sino en su progreso y en su última etapa de desarrollo, que por ello es la más concreta. Si la materia no se hubiera convertido en historia no tendríamos la explicación real y profunda de la realidad total. ${ }^{42}$

Para Ellacuría, este es el punto arranque de la filosofía marxiana, que parte de una inspiración hegeliana tanto en lo que tiene de dialéctica como de totalidad. La máxima densidad metafísica está en el proceso real en lo que tiene de formalmente histórico, y no en una presunta consideración de la materia a partir de lo que de ella dicen las ciencias naturales del siglo XIX.

\section{El materialismo histórico como filosofía de la praxis}

Para entender este planteamiento metafísico del materialismo histórico, Ellacuría analiza la crítica de Marx a la dialéctica hegeliana en los Manuscritos de $1844 . .^{43}$ En estos textos, Marx parte de la crítica de Feuerbach a Hegel:

La gran realización de Feuerbach es: 1) haber demostrado que la filosofía no es más que la religión hecha pensamiento y desarrollada a través del pensamiento y que debe ser igualmente condenada como otra forma y modo de existencia de la enajenación humana; 2) haber fundado el verdadero materialismo y la ciencia positiva al hacer de la relación social del "hombre con el hombre" el principio básico de su teoría; 3) haber opuesto a la negación de la negación que pretende ser el absoluto positivo, un principio autosuficiente fundado positivamente en sí mismo. ${ }^{44}$ 
De acuerdo a Marx, lo propio de Feuerbach consiste en afirmar que la filosofía (hegeliana) no es más que la religión puesta de una manera racional. Si esto es así, esa forma del pensamiento sigue siendo tan alienante como la religión. Pero se trata de la filosofía en sí y con independencia de sus condiciones reales. Este sería el primer aspecto en el que Feuerbach superaría la dialéctica hegeliana. Su segundo aporte es la fundamentación del verdadero materialismo y de la ciencia real como superación de las formas de pensamiento idealistas y alienadas, lo cual consiste en hacer de la relación del "hombre con el hombre" el principio fundamental de la teoría. Y el tercer aporte se refiere al método de esta nueva ciencia, que no puede ser el de la negación de la negación abstracta, sino algo radicado en un "principio autosuficiente", real, que se fundamente a sí mismo, aunque en Feuerbach esto se entiende genéricamente como lo "perceptible e indubitable" ${ }^{45}$
El problema es que Feuerbach afirma un materialismo abstracto y entiende al ser humano como si tuviera una esencia fija e inmutable, al margen de las relaciones sociales y la historia. Marx supera esta concepción y asume la visión histórica de la realidad que plantea Hegel, aunque no sus supuestos idealistas. Para Marx, el fallo de Hegel está en haber concebido el movimiento de la historia en forma idealista, pues "ha descubierto simplemente una expresión abstracta, lógica y especulativa del proceso histórico, que no es todavía la historia real del hombre como sujeto dado, sino solo la historia del acto de creación, de la génesis del hombre". ${ }^{46}$ Por esta razón, Hegel no reconoce que el extrañamiento (alienación, enajenación) de la autoconsciencia se origina en el extrañamiento de la vida real. El extrañamiento (la enajenación) no es un problema de consciencia, sino un problema de la vida real, y fundamentalmente del trabajo, que sería la expresión fundamental de la vida real:

Toda la historia de la enajenación y de la revocación de esta enajenación es, por tanto, sólo la historia de la producción del pensamiento abstracto, es decir, del pensamiento absoluto, lógico, especulativo. El extrañamiento, que constituye el interés real de esta enajenación y de la superación de esta enajenación, es la oposición del en sí y el para sí, de la conciencia y la conciencia de sí del objeto y el sujeto, es decir, la oposición en el pensamiento mismo entre el pensamiento abstracto y la realidad sensible o la existencia real sensible [...] No es el hecho de que el ser humano se objetive inhumanamente, en oposición a símismo, sino que se objetive diferenciándose y oponiéndose al pensamiento 
abstracto, lo que constituye la enajenación tal como existe y como debe ser superada. ${ }^{47}$

Aparentemente, Marx contradice su visión histórica de la realidad cuando afirma:

Ahora vemos cómo el naturalismo o humanismo consecuente se distingue tanto del idealismo como del materialismo y, al mismo tiempo, constituye su verdad unificadora. Vemos también cómo sólo el naturalismo es capaz de comprender el proceso de la historia universal. ${ }^{48}$

Ellacuría destaca que, en esta afirmación, "naturalismo" no significa de ningún modo la naturaleza que está dada en las ciencias naturales (este es justamente el 'materialismo' que debe ser superado), sino que se refiere al ámbito de realidad configurado por los individuos humanos concretos, tal y como estos se expresan en la actividad material que llevan a cabo con el fin de hacer sus vidas a partir de sus condiciones reales de existencia. El materialismo (incluyendo el de Feuerbach) que critica Marx propendería a creer que lo que ocurre en la historia y en la sociedad es lo mismo que lo que ocurre en la realidad física de la naturaleza, haciendo del individuo humano un ser pasivo que solamente realiza en la historia lo que las leyes naturales ya le han determinado a realizar. ${ }^{49}$

"Naturalismo" significa para Marx lo mismo que "humanismo", y en él ve la superación tanto del materialismo como del idealismo. El materialismo consiste aquí en no ver cómo de la naturaleza surge la historia como algo cualitativamente distinto que debe ser tratado de otra forma distinta a lo meramente natural. El idealismo consiste aquí en no ver la historia surgiendo de la naturaleza, sino verla como pura posición del espíritu. El "naturalismo", que luego se llamará materialismo histórico, es la verdad unificante de estas dos concepciones parcializadas: da razón del momento de conciencia y da razón del momento natural, precisamente porque los unifica. Espíritu y naturaleza forzosamente van juntos, el momento físico material más determinado y el momento ideal más libre; van unificados, pero de tal manera que el elemento consciente depende del momento material, aunque una vez que están constituidos se codeterminan estructuralmente porque forman una totalidad. En este sentido, el naturalismo, afirma Marx, "es capaz de comprender el proceso de la historia universal", pero -por lo mismo- es en términos de historia universal como debe explicarse el dinamismo procesual de la materia. $^{50}$

No hay, pues, una contradicción en la posición de Marx, sino 
una confirmación de la superación del materialismo naturalista o fisicista en un materialismo social e histórico. En el materialismo histórico, la realidad humana no está considerada como pura realidad natural, aunque $-y$ en eso radica su realismo- sostiene que el ser histórico implica el ser natural, pero este ser natural es entendido en términos al menos prehistóricos:

\begin{abstract}
El hombre es directamente un ser natural. Como ser natural y como ser viviente natural está dotado, por una parte de fuerzas y facultades naturales, que existen en él como tendencias y capacidades, como impulsos. Por otra parte, como ser natural, corpóreo, sensible, objetivo es un ser sufriente, condicionado y limitado, como los animales y las plantas. Los objetos de sus impulsos existen fuera de él mismo como objetos independientes de él, y no obstante son objetos de sus necesidades, objetos esenciales indispensables para el ejercicio y la confirmación de sus facultades. ${ }^{51}$
\end{abstract}

La realidad humana se parece a los animales y a las plantas en cuanto ser paciente, condicionado y limitado, pero tiene un momento de actividad que le es propio, irreductible a ese momento natural; su carácter natural estriba en que tiene físicamente fuera de sí lo que intrínsecamente necesita, y por ello este ser natural nunca quedará negado pero sí superado en la concreta realidad del ser humano:

\begin{abstract}
[...] el hombre no es simplemente un ser natural; es un ser humano natural. Es un ser para sí y, por tanto, un ser genérico, y como tal tiene que expresarse y confirmarse en el ser y en el pensamiento. En consecuencia, los objetos humanos no son objetos naturales como se presentan directamente, y el sentido humano, tal como se da inmediata y objetivamente, no es sensibilidad humana ni objetividad humana. Tampoco la naturaleza objetiva ni la naturaleza subjetiva se presentan directamente en una forma adecuada al ser humano. Y como toda cosa natural debe tener su origen, el hombre tiene su proceso de génesis, la historia, que es para él, sin embargo, un proceso consciente $y$, como tal, que se supera conscientemente a sí mismo. ${ }^{52}$
\end{abstract}

La realidad humana tiene su ser natural, pero su ser natural es propio y distinto de todo otro ser, es un "ser humano natural". Esto propio y distinto consiste en que el saber pertenece esencialmente 
a su esencia, que solo se actúa y se confirma en ese su saber de sí. La novedad consiste en que sus objetos y su modo de enfrentarlos es algo específico de él, y esta especificidad consiste en que sus objetos propios no se le dan inmediatamente, inmediatez que es lo propio de lo meramente natural. Como lo propio de la naturaleza es originar, también esta naturaleza hará brotar algo; pues bien el acto propio de este brotar humano es la historia, a la cual Marx interpreta aquí como superación de la naturaleza en la conciencia. Se concibe así la historia como una historia natural, es decir, como una historia que procede de la naturaleza, con lo cual se implica la historia con la naturaleza, aunque a través del saber y la conciencia.

Para Ellacuría, la lección que se puede sacar de este planteamiento de Marx para la constitución de una auténtica filosofía de la historia es que se debe superar un doble peligro: el concebir la realidad como pura naturaleza o el concebir la historia como puro resultado del hombre abstracto, que sería el extremo idealista que ignora las condiciones reales sin las que la negación de la negación -que es la superación de la enajenación- no es sino un regreso ideal e ilusorio que deja intacta la enajenación real. Para Marx, la forma plenaria en que se da la realidad es el hombre social en su proceso histórico; él es el principio de la realidad $y$, por tanto, el lugar al que hay que acudir para explicar todo lo demás. La realidad se da plenamente en la historia y en ella está el principio que explica toda la realidad. ${ }^{53}$

Así la filosofía de Marx supone para Ellacuría la constitución de un materialismo sui generis que, a la vez que critica y supera al idealismo, no recae en el naturalismo que ha caracterizado a los distintos tipos de materialismo, incluido el materialismo dialéctico. Un materialismo, por tanto, muy afín y en la línea del materialismo abierto zubiriano:

El Marx científico social [...] hará de toda la realidad económica una sola unidad real, de modo que esa realidad no será inteligible sino en la medida en que se tome unitaria y dinámicamente como una sola totalidad; no solo eso, sino que hará de esa realidad económica la última instancia de toda la realidad social e histórica, haciendo por tanto de toda la realidad natural e histórica, una sola realidad. ${ }^{54}$

La crítica de Marx a la concepción hegeliana de la historia y a su concepto de enajenación, en el sentido de que son resultado de una enorme mistificación de la realidad que sustituye la práctica 
real de los seres humanos concretos por la actividad de la Idea o del pensar abstracto, le lleva no solo a oponer una mera interpretación materialista a una interpretación idealista de la historia, sino a superar tanto el horizonte griego de la naturaleza y la movilidad como el horizonte de la nihilidad y la subjetividad que caracteriza a la filosofía europea desde Agustín a Hegel. ${ }^{55} \mathrm{El}$ principio de lo real no está ni en la naturaleza ni en ningún tipo de subjetividad, sea esta individual, transcendental o absoluta, sino en la vida práctica y sensible de los seres humanos. El materialismo de Marx se configura como un materialismo histórico por cuanto es una filosofía de la actividad humana, y no porque sea la aplicación a la historia de unas presuntas leyes dialécticas que regirían la evolución universal de la materia:

No es vana por ello la sustitución gramsciana del término marxismo por el de filosofía de la praxis, ni lo es tampoco la tesis de Labriola sobre la autonomía de la filosofía de la praxis respecto al idealismo y a los materialismos clásicos: frente al materialismo determinista se afirma el carácter activo y práctico de la realidad humana. Frente al idealismo, se sostiene que este carácter activo no reside en la actividad de un supuesto entendimiento transcendental, sino en la actividad sensorial, en la descuidada Sinnlichkeit de los clásicos. ${ }^{56}$
El gran esfuerzo de Ellacuría fue explotar la veta práxica de la filosofía zubiriana y proponer desde ella un modelo de filosofía realista y práctica superior a los ahora vigentes, cuya expresión máxima fue precisamente su Filosofía de la realidad histórica. ${ }^{57}$ De hecho, el mismo Ellacuría reconoce que Marx está presente implícitamente en muchos de los enfoques y contrastes que realiza en su obra, pero sin que ello signifique que se trate necesariamente de un revisionismo de Marx. "La razón es obvia: aquí no hemos pretendido una ciencia de la sociedad y de la historia sino, más modestamente, exponer principios metafísicos para la interpretación cabal de la persona en la sociedad y en la historia. Las matemáticas no son física ni técnica, pero ay de la física y de la técnica sin matemáticas" ${ }^{\prime 58}$

A pesar de que Ellacuría reconoce que, a nivel teórico, el marxismo es una enorme contribución al campo de una filosofía de la praxis, lo valora más como una crítica científica del capitalismo, como una ciencia social e histórica, que si bien ha proporcionado un valioso método de análisis científico para entender la sociedad y la historia, sobre todo en lo que tiene de dimensión económica-social, ${ }^{59}$ no se compara con la radicalidad de la metafísica zubiriana a la hora de fundamentar una teoría del ser humano, de la sociedad y de la historia. 


\section{Valoraciones críticas de Marx y del marxismo}

Esta interpretación de la filosofía marxiana no implica en Ellacuría desconocer sus errores y limitaciones, muchos de ellos derivados del estado de la ciencia de su época. El propio Marx y sobre todo Engels se vieron forzados a reconocer que la principialidad y primariedad que atribuyeron a lo económico en la marcha de la historia fue un tanto exagerada, al menos en la forma de enunciarla, en razón de la discusión con la filosofía idealista alemana, que era necesaria en los primeros momentos: "... ni el homo oeconomicus es el homo totalis ni la historia se reduce a ser una historia de los hechos económicos y del reflejo de estos en otras esferas teóricas" ${ }^{60}$

En realidad, a lo largo de la obra de Marx hay una ambigüedad en este punto: por un lado, está el rechazo al idealismo como unilateral, por dar preeminencia en la explicación histórica a los factores ideológicos e ignorar la importancia de los factores materiales. Por otra parte, está el rechazo al idealismo a través de la afirmación de su contrario, la prioridad absoluta y permanente de los factores materiales sobre todo lo demás, que dará paso al determinismo económico o economicismo. Este, por cierto, no recorre de ninguna manera toda la obra de Marx, pero dio lugar a un largo debate en el marxismo posterior en torno al papel de las denominadas "superestructuras" ideológicas, jurídicas y políticas en el proceso histórico y en el cambio social.

Es tal la complejidad presente en la obra marxiana que ha sido posible construir interpretaciones diferentes (y a veces radicalmente opuestas) de sus principales proposiciones teóricas, apelando en cada caso a la selección de determinados textos (y suprimiendo otros), que da pie a ambigüedades o tensiones existentes entre las formulaciones de Marx en relación con problemas teóricos y políticos centrales planteados en su obra. ${ }^{61}$

En primer lugar, está la tensión no resuelta entre necesidad y libertad, entre determinismo y voluntarismo. Por un lado, los seres humanos en la sociedad capitalista aparecen como producto inexorable de las leyes del movimiento del capital; incluso sus opiniones, sus gustos, son dictados por estas leyes. $\mathrm{Y}$, sin embargo, el ser humano es capaz de actuar conscientemente para transformar sus circunstancias y alcanzar su libertad. En segundo lugar, en Marx encontramos una crítica radical, pero también una admiración, de las fuerzas productivas desarrolladas por la burguesía en la sociedad capitalista. En tercer lugar, la obra marxiana contiene desde una epistemología centrada en el ser humano y en la praxis, en 
la que esta es el fundamento del conocimiento, hasta proposiciones que sirven de base para el realismo epistemológico y la teoría del reflejo desarrolladas después por Engels y Lenin.

Finalmente, hay que mencionar la observación crítica que Ellacuría hace del eurocentrismo de la filosofía de la historia de Marx y Engels, sobre todo al interpretar la historia de otras regiones del mundo en puntos esenciales. ${ }^{62}$ La sucesión histórica de modos de producción (sociedad sin clases, sociedad esclavista, sociedad feudal, sociedad capitalista, sociedad socialista) refleja un esquema de historia universal, a partir de su interpretación de la historia particular europea. Desde la óptica de este metarrelato, la visión de "los otros", de todas las experiencias de la humanidad, se manifiesta con toda claridad en algunos textos paradigmáticos de Marx sobre la India ${ }^{63}$ y de Engels sobre América Latina. Así, por ejemplo, Engels escribió: "En América hemos presenciado la conquista de México (por Estados Unidos), la que nos ha complacido... Es de interés de su propio desarrollo que México estará en el futuro bajo la tutela de Estados Unidos, mediante la ocupación de California, obtienen el predominio sobre el Océano Pacífico". ${ }^{64} \mathrm{Y}$ sobre Simón Bolivar, Marx escribía: "Hubiera sido pasarse de la raya querer presentar como Napoleón I al canalla más cobarde, brutal y miserable. Bolívar es el verdadero Soulouque (tirano de Haití entre 1849-1859). La fuerza creadora de mitos, característica de la fantasía popular, en todas las épocas ha probado su eficacia inventando grandes hombres. El ejemplo más notable de este tipo es, sin duda, el de Simón Bolívar". ${ }^{65}$

Son textos aislados que no necesariamente invalidan toda una teoría, pero son ejemplos que pueden ser caracterizados como muestras de la aplicación unilateral de una visión ilustrada de la historia, en la cual, como es el caso del pensamiento neoliberal contemporáneo, las particularidades históricas, culturales y sociales de las sociedades, y las formas de vida de sus poblaciones, pueden ser soslayadas en nombre de un omni-sistema interpretativo o metarrelato, el cual coloca a las naciones europeas a la vanguardia de la historia. Son textos que pueden tener cierta validez explicativa dentro del sistema interpretativo marxista, pero esto mismo demuestra que el mismo sistema es insuficiente para interpretar coyunturas históricas concretas en el contexto de lo que Engels Ilamaba "hechos histórico-universales". Un uso adecuado del marxismo en el estudio de la historia latinoamericana, sin dogmatismos ni aplicaciones mecánicas y con la conciencia de su historicidad, "puede presentar logros importantes así como los puede presentar 
también en el análisis de la realidad social latinoamericana". ${ }^{66}$

A nivel práctico-político, Ellacuría es consciente de la hegemonía incuestionable que el marxismo logró durante buena parte del siglo XX, no solo en los países que se Ilamaban "socialistas" y que vivían en el área de influencia de la ex URSS o de China continental, sino también dentro de los países capitalistas. ${ }^{67}$ Esto permitió que el marxismo se convirtiera en una fuente de pensamiento que impregnó la cultura occidental, y que incluso influyera en personas y grupos que se declaraban anticomunistas, haciéndolos más sensibles a la Ilamada "cuestión social". El marxismo dejó de ser el sistema de un determinado movimiento o corriente sociopolítica y se convirtió en uno de los elementos constitutivos de la modernidad y en una de las ideologías con mayor grado de difusión e influencia en el mundo. Más del 35 por ciento de la humanidad, perteneciente a las más diversas razas y culturas, llegó a vivir orientada y gobernada por la ideología marxista y por un régimen socio-político inspirado o guiado por el marxismo.

En el caso de El Salvador, Ellacuría señalaba a la altura de 1983 que el marxismo había inspirado importantes trabajo teóricos, especialmente en el campo de la economía, la historia y el análisis socio-político, jugó un papel importante en la concientización entre los sectores obreros y campesinos y -más aún- en los sectores universitarios y magisteriales. Pero quizá su mayor influencia en la marcha histórica del país fue la constitución, en la década de los setenta, de las organizaciones políticomilitares, que como fenómeno histórico -con independencia del juicio valorativo que se quiera hacer en torno a sus errores y aciertoscontribuyó en forma importante a la transformación del régimen político-militar autoritario que mantuvo su hegemonía por más de sesenta años.

Junto a estos logros hay que situar también los errores de la práctica marxista. Ellacuría distingue el marxismo latinoamericano del marxismo que se ha dado en otros continentes. Por lo menos la práctica marxista del subcontinente no tiene unas lacras iguales o semejantes a las que se dieron en otras parte del mundo. Ellacuría menciona el período staliniano en la Unión Soviética de 1937-1938, los graves fallos de los Ilamados "socialismos reales" en el Este europeo, el ahogamiento en sangre de los intentos de apertura a formas políticas democráticas en Hungría y Checoslovaquia, los excesos de la revolución cultural en los últimos años de Mao (1966-1969) o las purgas de Pol Pot en Camboya (1976-1978), entre otros casos: 
Sin exageración, antes con plena objetividad histórica, puede decirse que el marxismo ha cometido muchísimos menos crímenes y atropellos en América Latina que los perpetrados por el capitalismo y que ha sido mucho más respetuoso de los derechos fundamentales básicos de lo que han sido los regímenes capitalistas, como los de Argentina, Uruguay, Chile, Guatemala, Haití, etc., aunque en otros lugares de Latinoamérica no haya sido tan sanguinario, sin olvidar por eso que la catastrófica situación de las mayorías latinoamericanas ha sido el resultado histórico de regímenes capitalistas y del orden capitalista mundial. ${ }^{68}$

Ellacuría señala que, históricamente, el marxismo ha sido el gran contradictor de los sistemas capitalistas en América Latina, por su crítica radical al espíritu del capitalismo y el análisis que realiza de los mecanismos que lo sustentan, así como por su anuncio de la liberación humana a partir de la liberación del trabajo.

Ellacuría afirma que el marxismo latinoamericano ha sido más humano que el de otros continentes. Esta latinoamericanización del marxismo ha sido positiva, pues de alguna forma ha permitido responder más adecuadamente a las necesidades y a las identidades de las mayorías populares del continente. ${ }^{69}$ Sin embargo, señala que todavía falta mucho por hacer en esta línea. Es necesario historizar el análisis marxista de cara a la realidad histórica latinoamericana, para "humanizar los talantes y las políticas marxistas", ${ }^{70}$ superando así las recetas de los manuales y su aplicación ideologizada en la diversidad de situaciones concretas de los países latinoamericanos.

En el caso de El Salvador, quizás más que en ningún otro lugar, el marxismo salvadoreño surgió como la respuesta inevitable de un capitalismo desolador que generó las condiciones objetivas idóneas para constituir a su contrario, con el surgimiento de movimientos anticapitalistas de claro matiz marxista.

Sin embargo, Ellacuría reconoce que a pesar del enorme influjo que el marxismo ha tenido en la historia de El Salvador y Centroamérica y de su contribución a la liberación, el marxismo que ha predominado ha sido un marxismo ideologizado y mitificado, por encima del marxismo científico y crítico: "Marx y su trabajo teórico son perfectamente desconocidos en El Salvador y lo que de él opera son residuos estereotipados, que no hacen justicia a su obra y mucho menos la hacen a nuestra realidad". ${ }^{71}$ 
Para pensar los caminos de liberación en Centroamérica y en América Latina, el marxismo puede aportar mucho todavía, pero se necesita, según Ellacuría, "hacer una ciencia integral que respete la totalidad de los datos y no caiga en reduccionismos estériles. La lucha de clases, por ejemplo, "impulsada violentamente por el capitalismo, no tiene por qué ser planteada ni resuelta en términos de agudización de las contradicciones ni en términos de superioridad del odio sobre el amor". ${ }^{72}$ Los mismos marxistas deben ver, desde el propio Marx, los límites de su teoría y de su práctica. El marxismo es una ciencia social e histórica, cuyo objeto no es inmutable, sino que, al contrario, es en gran parte impredecible. "Si el marxismo fuera una especie de

\section{Notas}

1 Cfr. I. Ellacuría, "El hombre latinoamericano", lección de su curso de antropología filosófica impartido en la UCA en 1967. Archivo Ignacio Ellacuría, Universidad Centroamericana (UCA), San Salvador; I. Ellacuría, "Seguridad social y solidaridad humana", revista Estudios Centroamericanos, ECA, (253), 1969, pp. 357-366; I. Ellacuría, "Los derechos fundamentales y su limitación legal y política", en ECA (254), 1969 , pp. $435-450$.

2 En 1968 Ellacuría impartió en Bilbao una serie de conferencias sobre la violencia, que después fueron recogidas bajo el título "Violencia y cruz" en el capítulo quinto de su libro Teología política, publicado en 1973. También es importante mencionar el curso sobre filosofía perenne, como a veces piensan los repetidores escolásticos del materialismo dialéctico y del materialismo histórico, lo que necesitaría sería tan solo actualización. Pero si pretende ser ciencia y programa científico de acción, la revisión a fondo se impone en cada coyuntura distinta. Marx analizó de una manera metodológica válida una determinada forma de capitalismo, pero esa determinada forma de capitalismo ya no se da. Lo propio de la ciencia es, en efecto, crecer y cambiar sobre la base de algunos logros cuasi-definitivos". ${ }^{73}$ Incluso las prácticas anticapitalistas y la utopía comunista propiciadas por Marx deben ser repensadas, como lo hizo Lenin para su tiempo y para su circunstancia, que no son precisamente el tiempo y la circunstancia nuestros.

teología de la revolución que dictó en el Centro de Estudios Superiores para el Desarrollo (CESDE) de Medellín, Colombia, en julio de 1968. El curso partía del estado de revolución mundial producto de las luchas anticolonialistas y antiimperialistas que llevaban a cabo diversos movimientos de liberación nacional y grupos insurgentes y continuaba con el análisis del concepto y la necesidad de la revolución y de la teoría marxista de la revolución. El curso finalizaba con un análisis y valoración de la violencia, juzgada desde la doctrina cristiana. Cfr. "Progreso y revolución", en ECA (258), 1970, pp. 152-154; "Teología de la revolución y evangelio", en ECA (266), 1970, pp. 581-584.

3 Cfr. J. Hernández-Pico, "Diagnóstico socio-teológico sobre la realidad de 
Centroamérica y Panamá”, en ECA (268), 1971.

4 Cfr. Cardoso-Faletto, Dependencia y desarrollo en América Latina, $3^{a}$ edición, México, Siglo XXI, 1971. El trabajo de Cardoso y Faletto fue uno de los primeros que le dio status científico al concepto de dependencia al colocarlo en el centro de la discusión académica sobre el desarrollo. Este enfoque fue desarrollado por otros cientistas sociales, entre los que destacaban: Aníbal Quijano, Ruy Mauro Marini, Theotonio Dos Santos, André Gunder Frank, Francisco Weffort y Samir Amín. Cfr. varios, América Latina: dependencia y subdesarrollo, San José Costa Rica, EDUCA, 1975.

5 Cfr. I. Ellacuría, "Socialismo latinoamericano", lección XII del curso sobre filosofía política impartido en la UCA de San Salvador, de agosto a noviembre de 1973. Archivo Ignacio Ellacuría, Universidad Centroamericana (UCA), San Salvador. En la introducción de esta lección, Ellacuría señalaba que el socialismo latinoamericano era un movimiento indiferenciado tanto en su pensamiento como en su realización, pero con algunos rasgos esenciales comunes, entre los cuales destacaba el contagio de sus autores a partir de la realidad histórica latinoamericana y su dependencia del análisis marxista de la sociedad y de la historia. El significado del término 'socialismo' provenía del intento de superar el individualismo liberal dando prioridad a lo social. En esta línea, el socialismo latinoamericano propendía a la búsqueda y realización de formas políticas socialistas aunque no necesariamente de estricta realización marxista. Aceptaba el planteamiento estructural del marxismo que postula la estructura económica como la instancia fundamental que condiciona no solo direcciones estructurales, sino también los comportamientos subjetivos, pero admitía la complejidad de la estructura: lo económico tiene una importancia singular, pero deben considerarse otras variables cuya dependencia de la variable económica no es fija ni unívoca. En cualquier caso, era el análisis de la realidad lo que debe dirigir la teoría y no viceversa. A partir de aquí, el socialismo latinoamericano insistía en la actuación directa sobre la conciencia de las masas populares, con lo que se reconocía explícitamente la autonomía relativa de lo subjetivo respecto de las estructuras objetivas, contrario a lo postulado por el marxismo ortodoxo. Además, expresaba a la vez un escepticismo ante la afirmación de que el mero cambio de estructuras cambiaría sin más la subjetividad. Por ello hacía hincapié en la concientización (Freire) como raíz de una plena liberación

6 Cfr. A. Gunder Frank, "El desarrollo del subdesarrollo", en varios, América Latina: dependencia y subdesarrollo, op. cit.

7 I. Ellacuría, "Teorías económicas y relación entre cristianismo y socialismo", Concilium (125), mayo 1977, p. 286.

8 Cfr. Th. Dos Santos, "La crisis de la teoría del desarrollo y las relaciones de dependencia en América Latina”, en varios, La dependencia político-económica de América Latina, Siglo XXI, México, 1973.

9 I. Ellacuría, "Socialismo latinoamericano", op. cit.

10 I. Ellacuría, "Teorías económicas y relación entre cristianismo y socialismo", op. cit., p. 286.

11 I. Ellacuría, "Socialismo latinoamericano", op. cit.

12 Ibidem. 
13 I. Ellacuría, "Teorías económicas y relación entre cristianismo y socialismo", op. cit., p. 288.

14 Cfr. J. Hernández-Pico, op. cit., p. 26.

15 En otras palabras, no se trata de filosofar por filosofar, o filosofar por mera erudición o por el prurito de conocer para tener un mejor conocimiento de hechos pasados o presentes; esto es, transmitir o construir un saber abstracto y ahistórico, otra interpretación más, que deje intocada la dinámica de la realidad socio-histórica concreta, en la que se juega la realización misma del ser humano y de la realidad total.

16 Cfr. X. Zubiri, Los problemas fundamentales de la metafísica occidental, Alianza Editorial-Fundación Xavier Zubiri, Madrid, 1994, pp. 248-249.

17 Cfr. Introducción del curso Hegel y el método dialéctico (1973), Archivo Ignacio Ellacuría, UCA, San Salvador. Publicado en I. Ellacuría, Cursos universitarios, UCA Editores, 2009.

18 Filosofía de la realidad histórica, UCA Editores, San Salvador, 1990, pp. 535-536.

19 Ellacuría distingue entre el materialismo dialéctico formulado por Engels (cf. Dialéctica de la naturaleza y el AntiDubring) y la filosofía de Marx, a la que él denomina aquí 'materialismo histórico'.

20 Cfr. I. Ellacuría, "La metafísica del marxismo", lección del curso Metafísica I (1974), Archivo Ignacio Ellacuría, UCA, San Salvador. Publicado en I. Ellacuría, Cursos universitarios, UCA Editores, San Salvador, 2009.

$21 C f r$. I. Ellacuría, "Teología de la liberación y marxismo", op. cit., p. 121.

22 Cfr. I. Ellacuría, Apuntes del curso Marx en la historia de la filosofia: "Marx y los jóvenes hegelianos" (1973), Archivo Ignacio Ellacuría, UCA.

23 I. Ellacuría, "La desmitificación del marxismo", en Escritos politicos, t.1, UCA Editores, San Salvador, 2005, p. 286.

24 Cfr. I. Ellacuría, "La salida de la incertidumbre de Descartes", lección del curso de Metafísica I (1974), op. cit.

25 Cfr. I. Ellacuría, "El tema de lo transcendental en Kant", lección del curso Metafísica I (1974), op. cit.

26 Cfr. I. Ellacuría, "Función liberadora de la filosofia”, en ECA (435-436), 1985, p. 52.

27 Cfr. I. Ellacuría, "La razón y el absoluto en la dialéctica de Hegel", lección del curso Metafísica I (1974), op. cit.

28 I. Ellacuría, "El objeto de la filosofía", en ECA (396-397), 1981, p. 977.

29 Cfr. I. Ellacuría, "La metafísica del marxismo", op. cit.

30 F. Engels, Ludwig Fenerbach y el fin de la filosofía clásica alemana, Editorial Progreso, Moscú, 1975, pp. 15 y 16. Cfr. Ludwig Feuerbach und der Ausgang der klassischen deutschen Pbilosophie, Stuttgart, 1888, p. 15. Citado por Ellacuría en "La metafísica del marxismo", op. cit.

31 V. I. Lenin, Materialismo y Empiriocriticismo, Ediciones Tecolut, San Salvador, 1971, pp. 98 у 207. Cfr. Materialismus und Empiriokriticismus, Moscau, 1947, pp. 22 y 247. Citado por Ellacuría en "La metafísica del marxismo", op. cit.

32 I. Ellacuría, Filosofía de la realidad histórica, UCA Editores, San Salvador, p. 54.

33 Cfr. I. Ellacuría, "La metafísica del marxismo", op. cit.

34 Cfr. D. Gracia, "Materia y sensibilidad", en Realitas II. Seminario Xavier Zubiri, Editorial Labor, Madrid, 1976, pp. 224-241. 
35 Cfr. I. Ellacuría, Filosofía de la realidad histórica, op.cit., p. 54.

36 La triple contraposición que establece el materialismo dialéctico, pensar-ser, espíritu-naturaleza, Dios creador-materia o mundo eterno, indicaría que este no solo está influido por el horizonte de la naturaleza, sino también por el horizonte cristiano de la creación, dentro del cual busca una vía no teológica. La eternidad de la materia se propone como alternativa al acto creador. Lo mismo se puede decir de su tesis sobre el movimiento de la materia. Cf. I. Ellacuría, Filosofía de la realidad histórica, op. cit., p. 58.

37 Cfr. F. Engels, Dialéctica de la naturaleza, Editorial Grijalbo, México, 1961, pp. 41-62. Cfr. Dialektik der Natur, en K. Marx y F. Engels, Werke, t. 20, Berlín, Dietz, 1969, p. 311-327.

38 Cfr. Ibidem, p. 41.

39 Cfr. Ibídem.

40 Cfr. I. Ellacuría, "La metafísica del marxismo", op. cit.

41 K. Marx, Manuscritos de 1844, citado por Jakubowski, F., Las superestructuras ideológicas en la concepción materialista de la historia, Madrid, 1973, p. 19.

42 Cfr. I. Ellacuría, "La metafísica del marxismo", op. cit.

43 Cfr. Ibidem.

44 K. Marx, Manuscritos de 1844, UCA Editores, San Salvador, 1987, p. 115. Cfr. "Kritik der Hegelschen Dialektik und Philosophie überhaupt", en Frühe Schriften, I, Darmstadt, 1971, p. 639.

45 Ibídem.

46 Ibidem, p. 116.

47 Ibidem, pp. 118-119.

48 Ibidem, p. 125.
49 Cfr. "La metafísica del marxismo", op. cit.

50 Cfr. Ibidem.

51 K. Marx, Manuscritos de 1844, op. cit., p. 125.

52 Ibídem, p. 127.

53 Cfr. I. Ellacuría, "La metafísica del marxismo", op. cit. Justamente por ello, Marx explica, a partir de esa realidad principial, todas las otras formas sociales superestructurales y las ideologías: "En la producción social de su existencia, los hombres establecen determinadas relaciones, necesarias, independientes de su voluntad; estas relaciones de producción corresponden a un grado de desarrollo de sus fuerzas productivas materiales. El conjunto de estas relaciones forma la estructura económica de la sociedad, la base real sobre la cual se eleva una superestructura jurídica y política, y a las que corresponden formas determinadas de conciencia social. El modo de producción de la vida material domina en general el desarrollo de la vida social, política e intelectual. No es la conciencia de los hombres la que determina su existencia; es, por el contrario, su existencia social la que determina su conciencia". K. Marx, "Prólogo a la contribución de la economía política", citado por Jakubowski, op. cit., p. 47.

54 I. Ellacuría, "El objeto de la filosofía", op. cit., p. 965.

55 Cfr. A. González, "Prólogo", en K. Marx, Manuscritos de 1844, op. cit. De acuerdo al autor, esto sitúa a Marx en el horizonte de la filosofía contemporánea, a la altura de pensadores como Nietzsche, Wittgenstein, Husserl, Heidegger o Zubiri, en quienes es central el problema de la superación de la "metafísica de la subjetividad" de la era cartesiana. Esta es justamente la interpretación de Ellacuría. 
56 Ibidem, p. 19.

57 Cfr. D. Gracia, "Filosofía práctica", op. cit., p. 340.

58 En la nota de pie de página 145 del texto del curso Persona y comunidad en Zubiri (1974), en Archivo Ignacio Ellacuría, UCA, San Salvador.

$59 C f$. I. Ellacuría, "La desmitificación del marxismo", op. cit., 2005, pp. 284 ss.

60 Ibidem, p. 286.

61 Cf. E. Lander, "Marxismo, eurocentrismo y colonialismo", en A. Borón, J. Amadeo, S. González (compiladores), La teoría marxista boy, CLACSO, Buenos Aires, 2006, pp. 236 ss.

62 I. Ellacuría, "La desmitificación del marxismo", op. cit., p. 288.
63 K. Marx, "The British rule in India" (1853), en K. Marx, Surveys from Exile, Penguin, Harmondsworth, 1973, pp. 306-307.

64 Marx-Engels, Materiales para la historia de América Latina, Cuadernos de Pasado y Presente, México, 1980, p. 256.

65 Citado por Ellacuría en "La desmitificación del marxismo", op. cit., p. 288.

66 Ibidem.

67 Ibidem, p. 282.

68 Ibidem, p. 289.

69 Ibidem.

70 Ibidem.

71 Ibidem, p. 284.

72 Ibidem.

73 Ibidem. 